\title{
Implicit Learning of Color-Word Associations Using a Stroop Paradigm
}

\author{
Gail Musen and Larry R. Squire
}

\begin{abstract}
Our experiments asked whether implicit learning occurs for novel nonverbal associations. We presented subjects with color names printed in incongruent colors; subjects were asked to name the color in which the word was printed. In Experiment 1, each of 7 color words were associated with the same incongruent color across 6 blocks of trials, and then the color-word associations were abruptly changed. Both control subjects and patients with amnesia reduced their color-naming times across the first 6 trial blocks, and naming times increased when the color-word associations were changed. In Experiment 2, similar results were obtained when neutral words were associated with colors. In Experiment 3, we found that naming times were not disrupted when an irrelevant dimension (typecase) was changed. Finally, in Experiment 4, we found that the effect persisted across a 5-min delay. These studies provide evidence that implicit learning occurs for nonverbal associations and is independent of the brain structures damaged in amnesia.
\end{abstract}

The nature of implicit memory has been a major focus of memory research in recent years (for recent reviews, see Schacter, Chiu, \& Ochsner, 1993; Squire, Knowlton, \& Musen, 1993). One important issue has been to identify the kinds of information that can be supported by implicit memory. One early proposal was that implicit memory depends on the activation of preexisting memory representations. For example, in the case of priming effects, it was supposed that studying an item activates a preexisting memory representation for that item, such that the same item is more readily processed when it is subsequently encountered. However, this idea has been seriously challenged by evidence that control subjects show priming for nonwords (Cermak, Talbot, Chandler, \& Wolbarst, 1985; Cermak, Verfaellie, Milberg, Letourneau, \& Blackford, 1991; Feustel, Shiffrin, \& Salasoo, 1983; Jacoby, 1983; Jacoby \& Dallas, 1981; Rueckl, 1990; Salasoo, Shiffrin, \& Feustel, 1985; Whitlow \& Cebollero, 1989) as well as for nonverbal material such as simple line patterns and line figures (Kersteen-Tucker, 1991; Musen \& Treisman, 1990; Schacter, Cooper, \& Delaney, 1990). Thus, priming need not always depend on the activation of preexisting memory representations. Instead, a new represen-

Gail Musen (now at Department of Psychology, Barnard College, Columbia University) and Larry R. Squire, Veterans Affairs Medical Center and Department of Psychiatry, University of California, San Diego.

This research was supported by the Medical Research Service of the Department of Veterans Affairs, National Institute of Mental Health (NIMH) Grant MH24600, the Office of Naval Research, the McKnight Foundation, and an NIMH postdoctoral fellowship to Gail Musen (MH09858).

We thank Joyce Zouzounis, Teresa Doksum, Kathleen Fuchs, and Kamilla Willoughby for research assistance; Daniel Schacter, Marilyn Smith, and an anonymous reviewer for helpful comments on an earlier version of this article; and Paul Clopton for developing the computer software.

Correspondence concerning this article should be addressed to Larry R. Squire, Veterans Affairs Medical Center (9116A), 3350 La Jolla Village Drive, San Diego, California 92161. tation capable of supporting priming can be established at the time of study.

This conclusion gains additional strength from studies showing that amnesic patients exhibit fully intact priming after a single presentation of nonwords (Haist, Musen, \& Squire, 1991) or after single presentations of nonverbal material (Gabrieli, Milberg, Keane, \& Corkin, 1990; Musen \& Squire, 1992; Schacter, Cooper, Tharan, \& Rubens, 1991). Because amnesic patients exhibit impaired declarative memory, fully normal performance on a memory task implies that the task does not rely materially on declarative memory. If declarative memory were contributing to performance, then one would expect (in the absence of floor and ceiling effects) that control subjects would perform significantly better than patients with amnesia.

Another area of active research has involved the question of whether implicit memory can support the acquisition of new associations. In one early report, Graf and Schacter (1985) reported that control subjects could learn new associations implicitly in a single trial, using a wordstem completion paradigm. That is, after studying word pairs such as WINDOW-REASON, subjects tended to complete word stems with study words more often when presented with same-context pairs (wINDOw-REA _ _ - ) than differentcontext pairs (OFFICER-REA _-_). However, this effect has not been reliably demonstrated in amnesic patients (Cermak, Bleich, \& Blackford, 1988; Mayes \& Gooding, 1989; Shimamura \& Squire, 1989). Shimamura and Squire (1989) found that the priming of new associations in amnesic patients was correlated positively with scores on the General Memory Index of the Wechsler Memory ScaleRevised (WMS-R). They proposed that priming of new associations, in addition to any contribution from implicit memory, also depends crucially on declarative (explicit) memory because declarative memory is needed at study to form the initial link between the stimuli. This proposal explains why priming of new associations can be observed in control subjects, as well as in patients with mild but not severe amnesia, and why in control subjects this phenomenon can be dissociated from explicit memory (Graf \& 
Schacter, 1985, 1987, 1989; Schacter \& Graf, 1986, 1989).

One study did report implicit learning of new associations (word pairs) in memory-impaired individuals after a single learning trial, as measured by reading speed (Moscovitch, Winocur, \& McLachlan, 1986). However, separate statistics for the individual subject groups were not reported, so it is not clear whether the memory-impaired group itself, when considered separately, could learn new associations. In a series of four experiments with amnesic patients that used similar paradigms, Musen and Squire (1993) found little or no implicit learning of new associations between unrelated pairs of words after a single study trial. However, such learning was readily apparent after multiple learning trials. We proposed that implicit memory is best suited for the gradual acquisition of new associative information but is not suited for rapid (one-trial) associative learning.

Implicit learning of new associations across many trials has also been reported by Hartman, Knopman, and Nissen (1989). In this case, the acquired associations involved interitem associations between repeating sequences of words, not associations between two words presented together. Four words were presented on a screen one word at a time, and the order of the words followed a repeating $10-$ trial sequence. The subject's task was to respond as quickly as possible to each word by naming the category to which the word belonged (e,g., the correct response to robin was bird). Subjects gradually improved their reaction times (RTs) when the four words recurred in a repeating sequence, as compared with a control condition in which the sequence of words was random. This finding indicates that subjects learned interitem associations, that is, links between two items in a sequence rather than between two items that appear within a single trial. Other examples of gradual, implicit learning have also been reported that depend on associations between sequentially presented items (Cleeremans \& McClelland, 1991; Hartman et al., 1989; Lewicki, Czyzewska, \& Hoffman, 1987; Willingham, Nissen, \& Bullemer, 1989). The studies reviewed here provide evidence for gradual (and implicit) within-trial acquisition of new associations involving word pairs and for gradual acquisition of between-trials information (i.e., interitem associations) of sequential information.

In the present study, we asked whether gradual (and implicit) learning of new associations can occur within a trial for information other than word pairs. We presented subjects with unitized stimuli (words that were the names of colors printed in incongruent colors). The subject's task was to name the color that a word was printed in as quickly and accurately as possible (Stroop, 1935). For example, if the word green was printed in the color red, the correct response was red. The two elements to be associated were a word and a color. The critical feature of the study was that each of seven color words was associated with the same seven incongruent colors for six repetitions. After six repetitions of each color word had been presented, the color-word associations were changed without forewarning. If subjects can learn associations between the color word and the color in which it is printed, then naming times for each color word should gradually decrease across the six blocks of trials and then increase again when the color-word associations are changed.

Changes in the color of a word might also be viewed as a change in a single feature of a unified stimulus rather than as a change in a color-word association. In this view, a change in the color of a word is analogous to changing its type font or the modality of presentation. Priming effects are often sensitive to changes in the specific visual details of the stimulus (Cave \& Squire, 1992; Jolicouer, 1985; Masson, 1986; Roediger \& Blaxton, 1987; Scarborough, Cortese, \& Scarborough, 1977). Yet, in some studies changes in specific visual details reduced the priming effect only when the change was extreme (such as an unusual font; Graf \& Ryan, 1990; Jacoby \& Hayman, 1987). Musen and Squire (1991) did not observe any reduction in reading speed for nonwords when the type changed from lowercase to uppercase. Additionally, changes in left-right orientation, in size, or in the color of novel line patterns do not appear to affect the magnitude of priming (Biederman \& Cooper, 1991, 1992; Cooper, Schacter, Ballesteros, \& Moore, 1992; Treisman, 1992).

Treisman's (1992) findings are particularly relevant to the present study because color change is involved in both cases. In Treisman's study, subjects first studied line patterns and then tried to reproduce line patterns after either new or old patterns were briefly presented. The priming effect, that is, the beneficial effect of prior study on the ability to reproduce the patterns immediately after they were briefly presented, was not affected when the color of the line patterns was changed between the study phase and the brief presentation. It may have been important that the reproduction task did not require subjects to access color information about the stimuli during the response. If instead color were made an integral part of the response, changes in the color of the stimulus might reduce the priming effect. Our study makes the color an integral part of the response by requiring that the subject name the color of the stimulus on each trial.

The Stroop task requires subjects to process both features of the stimuli (the color and the word; Kahneman \& Treisman, 1984). Because the color must be named, subjects must process the colors, and, because word reading is automatic, the words are also processed. In Treisman's (1992) study, color was irrelevant and may not have been encoded. In contrast, in a multiple-trial visual search task, Treisman reported that irrelevant features did affect performance.

The question of interest in Experiment 1 is whether priming is reduced when a color and a word are processed together and the color is subsequently changed. In this way, we investigated whether new nonverbal associations can be acquired implicitly across multiple trials. To test that the learning is implicit and not contaminated by declarative memory strategies, we asked whether patients with amnesia could acquire this information and whether they could acquire it at the same rate as control subjects. In Experiment 2, neutral words (e.g., sock and window) were associated with colors to determine whether associative learning was dependent on the opportunity to reduce the strong interference between color names and colored words. In Experiment 3, we asked whether changing an irrelevant feature (i.e., typecase) produces the same pattern of results as changing the color-word 
associations. In this way, we directly tested whether implicit learning of associative information requires that attention be paid to the features of the stimuli that are to be associated. Finally, in Experiment 4, we examined whether the learning of new associations is independent of immediate memory, which is intact in amnesia.

\section{Experiment 1}

In this experiment, patients with amnesia and control subjects named colored words as quickly as possible. Naming times were measured across six trial blocks (seven color words presented six times each). After the sixth trial block, the color-word associations were changed such that each color word was now associated with a second, incongruent color. After the color-naming task, subjects were given a recognition test to ascertain whether subjects could report for each color name the two colors in which it had been printed during the experiment. Finally, a questionnaire concerning details of the experimental procedure was given to both subject groups to determine whether the ability to learn new associations was related to the ability to recall specific information about the test situation.

\section{Method}

Subjects. We tested 8 patients with amnesia ( 5 men and 3 women), all of whom have participated in several studies in our laboratory. Three of the patients have alcoholic Korsakoff's syndrome. They had participated either in a magnetic resonance imaging (MRI) study (Squire, Amaral, \& Press, 1990) or in a quantitative computerized tomography study (Shimamura, Jernigan, \& Squire, 1988), which demonstrated marked reductions in the volume of the mammillary nuclei, reduced thalamic tissue density, and frontal lobe atrophy. Of the 5 other patients, 1 (JL) has bilateral hippocampal pathology that was identified with MRI (Kritchevsky \& Squire, 1993; Press, Amaral, \& Squire, 1989). Another patient became amnesic as a result of anoxia associated with cardiac arrest (AB). Patient LJ gradually became amnesic between September 1988 and February 1989 without any known precipitating event.
Her memory impairment has remained stable since that time. Two patients (NA and MG) had diencephalic lesions confirmed by MRI (for NA, Squire, Amaral, Zola-Morgan, Kritchevsky, \& Press, 1989; for MG, unpublished observations). Patient MG became amnesic following a bilateral medial thalamic infarction. Patient NA became amnesic, primarily for verbal material, following a stab wound to the left diencephalic region with a miniature fencing foil (Kaushall, Zetin, \& Squire, 1981; Teuber, Milner, \& Vaughan, 1968). All 8 patients have been well characterized with neuropsychological tests, which document both the severity of the memory impairment and its selectivity (Tables 1 and 2). The present study was concerned with the overall performance of the patients with amnesia, and the patients are therefore presented here as a single group.

The 8 patients with amnesia averaged 62 years of age (range $=$ 53-74) and 12.8 years of education (range $=9-20$ ). They had an average Wechsler Adult Intelligence Scale-Revised (WAIS-R) score of 105.8. Individual IQ and WMS-R index scores appear in Table 1. Immediate and delayed (12-min) recall of a short prose passage averaged 5.5 and 0 segments, respectively ( 21 segments total; Gilbert, Levee, \& Catalano, 1968). Scores on other memory tests appear in Table 2. Note that the scores on the word recall test in Table 2 are above zero because on this test of immediate recall several items can be retrieved from immediate memory, which is intact in amnesia. In addition, the mean score on the Dementia Rating Scale (Mattis, 1976) was 134.5 (maximum score $=144$, range $=125-143$ ), with most points lost on the memory subportion of the test (5.6 points). The average score on the Boston Naming Test was 55.5 (range $=47-59$ ). Scores for control subjects on these same tests can be found elsewhere (Janowsky, Shimamura, Kritchevsky, \& Squire, 1989; Squire et al., 1990).

Seven men and 5 women served as a control group for the patients with amnesia. They were either employees or volunteers at the San Diego Veterans Affairs Medical Center or were retired employees from the University of California, San Diego. They averaged 62 years of age (range $=55-73$ ) and 14.3 years of education (range $=10-18$ ) and obtained WAIS-R subtest scores of 21.1 for Information and 55.0 for Vocabulary (compared with 19.9 and 57.1, respectively, for patients with amnesia). Immediate recall and delayed recall of the short prose passage were 6.4 and 5.2 segments, respectively.

Materials. Seven color words (purple, green, yellow, orange, blue, white, and red) were presented one at a time in incongruent colors in the center of a monitor screen measuring $26.7 \mathrm{~cm} \times 20.3$

Table 1

Patient Characteristics

\begin{tabular}{|c|c|c|c|c|c|c|c|c|}
\hline \multirow[b]{2}{*}{ Patient } & \multirow{2}{*}{$\begin{array}{c}\text { Age } \\
\text { (yrs.) }\end{array}$} & \multirow[b]{2}{*}{ Etiology } & \multirow[b]{2}{*}{ WAIS-R } & \multicolumn{5}{|c|}{ WMS-R } \\
\hline & & & & Attention & Verbal & Visual & General & Delay \\
\hline VF & 71 & Korsakoff & 103 & 101 & 78 & 72 & 72 & 66 \\
\hline PN & 63 & Korsakoff & 99 & 81 & 77 & 73 & 67 & 53 \\
\hline $\mathrm{RC}$ & 74 & Korsakoff & 106 & 115 & 76 & 97 & 80 & 72 \\
\hline MG & 59 & Thalamic infarction & 111 & 113 & 89 & 84 & 86 & 63 \\
\hline NA & 52 & Penetrating brain injury & 109 & 102 & 67 & 89 & 68 & 71 \\
\hline $\mathrm{LJ}$ & 53 & Unknown & 98 & 105 & 83 & 60 & 69 & $<50$ \\
\hline $\mathrm{JL}$ & 71 & Unknown & 116 & 122 & 73 & 83 & 74 & 58 \\
\hline $\mathrm{AB}$ & 53 & Anoxia & 104 & 87 & 62 & 72 & 54 & $<50$ \\
\hline$M$ & 62 & & 105.8 & 103.2 & 75.6 & 78.8 & 71.2 & 60.4 \\
\hline
\end{tabular}

Note. $\quad$ WAIS-R $=$ Wechsler Adult Intelligence Scale-Revised; WMS-R = Wechsler Memory Scale-Revised. The WAIS-R and each of the five indexes of the WMS-R yield a mean score of 100 in the normal population with a standard deviation of 15. The WMS-R does not provide numerical scores for subjects who score below 50 . Therefore, the two values below 50 were scored as 50 for computing a group mean. Korsakoff = alcoholic Korsakoff's syndrome. 
Table 2

Performance of Patients on Standard Memory Tests

\begin{tabular}{|c|c|c|c|c|c|c|}
\hline Patient & $\begin{array}{l}\text { Diagram } \\
\text { recall }\end{array}$ & $\begin{array}{c}\text { Paired } \\
\text { associates }\end{array}$ & $\begin{array}{c}\text { Word } \\
\text { recall } \\
(\%)\end{array}$ & $\begin{array}{c}\text { Word } \\
\text { recognition } \\
(\%)\end{array}$ & $\begin{array}{c}50 \\
\text { words }\end{array}$ & $\begin{array}{c}50 \\
\text { faces }\end{array}$ \\
\hline VF & 8 & $0-0-0$ & 27 & 91 & 27 & 31 \\
\hline PN & 2 & $1-1-1$ & 29 & 83 & 31 & 31 \\
\hline $\mathrm{RC}$ & 3 & $0-0-3$ & 19 & 85 & 37 & 30 \\
\hline MG & 0 & $0-0-2$ & 52 & 81 & 30 & 34 \\
\hline $\mathrm{JL}$ & 1 & $0-0-0$ & 40 & 93 & 31 & 20 \\
\hline NA & 17 & $0-0-2$ & 49 & 93 & 34 & 42 \\
\hline $\mathrm{LJ}$ & 3 & $0-0-0$ & 40 & 93 & 33 & 29 \\
\hline $\mathrm{AB}$ & 4 & $1-1-2$ & 33 & 83 & 32 & 33 \\
\hline$M$ & 4.8 & $0.2-0.2-1.2$ & 36.1 & 87.8 & 31.9 & 31.2 \\
\hline Controls & 20.6 & $5.6-7.6-8.8$ & 71 & 97 & 41.1 & 38.1 \\
\hline
\end{tabular}

Note. For controls, $N=8$. The diagram recall score is based on delayed (12-min) reproduction of the Rey-Osterrieth figure (Osterrieth,

1944; maximum score $=36$ ). The average score for copying the figure was 26.5 , a normal score (Kritchevsky, Squire, \& Zouzounis, 1988).

The paired associates score is the number of word pairs recalled on three successive trials (maximum score $=10 /$ trial). The word recall score is the percentage of words recalled out of 15 across five successive study-test trials (Rey, 1964). The word recognition score is the percentage of words identified correctly across five successive study-test trials (yes-no recognition of 15 new words and 15 old words). The score for words and faces is based on a 24-hr recognition test of 50 words or 50 faces (modified from Warrington, 1984; maximum score $=50$, chance $=25$ ). The mean scores for normal subjects shown for these tests are from Squire and Shimamura (1986). Note that NA is not severely impaired on nonverbal memory tests because his brain injury is primarily left unilateral.

$\mathrm{cm}$ (e.g., the word green was always printed in the color purple). The words were approximately $6 \mathrm{~mm}$ high and ranged from $1.9 \mathrm{~mm}$ to $3.5 \mathrm{~mm}$ long. The words were presented using an IBM laptop computer in conjunction with a computer graphics adaptor (CGA) graphics monitor. A voice-activated relay was controlled by the computer to collect RT responses to the color words. The subjects were seated approximately $52 \mathrm{~cm}$ from the screen such that each word subtended approximately $3.4^{\circ}$ of visual angle vertically and between $2.1^{\circ}$ and $3.8^{\circ}$ of visual angle horizontally. The experimenter recorded trials as invalid if the subject made an error in color naming (i.e., when the subject named the word rather than the color it was printed in or when the voice-activated relay was not triggered correctly). This procedure resulted in the elimination of $8 \%$ of the trials for patients with amnesia and $3.2 \%$ for control subjects.

Design and procedure. Seven color words were presented six times, always in the same incongruent color, for a total of 42 trials. The order of words was randomized in blocks of seven so that the mean number of trials between repetitions of the same word was always even. The same word (and color) never appeared consecutively. After 42 trials, the color-word associations were abruptly changed such that the same seven color words now appeared in different incongruent colors (e.g., the word green, which was always printed in the color purple for the first six blocks, was printed in orange thereafter). An additional 42 trials were then presented using the new color-word associations (seven color words presented six times each). These two sets of color-word associations were counterbalanced across subjects so that half the subjects received Set 1 as the first set of associations and half the subjects received Set 2 as the first set of associations.

For each word that was presented, the subject's task was to name as quickly as possible the color in which the word was printed. For example, if the word green appeared in the color purple, the correct response was purple. Coincident with the subject's response, the stimulus word disappeared from the screen and a new word replaced it. The RTs across the first six blocks of trials were recorded automatically. These RTs were compared with the RTs across the second block of six trials in which the seven colors were each associated with a different, incongruent color.
After the color-naming test, all subjects were given a recognition memory test for the color-word associations. In this test, seven rows of $x$ s appeared on the monitor, and each row was printed in one of the seven colors that had been used in the test. Subjects were then asked for each of the seven color names, "Which two colors do you think the word was printed in?" Chance performance on this test was $33.3 \%$. After this test, an eight-item questionnaire was given (three alternative, forced choice). These eight questions asked about various aspects of the task such as how many words were presented at one time, what kinds of words were presented, and how many different colors were on the screen at one time.

\section{Results}

The RTs for all 84 trials were divided into 12 blocks of 7 trials each. The RTs decreased rapidly across the first several blocks of trials, indicating that subjects learned the associations between the color names and the colors (Figure 1). The RTs abruptly increased for both groups when the color-word associations were changed and then decreased again as subjects had repeated experience with the new associations. Statistical tests confirmed these impressions. First, a two-way analysis of variance (ANOVA) revealed that there was a significant block effect during the first portion of the learning curve (i.e., when the color words were associated with the first color), $F(5,90)=20.0, p<.001, M S_{\mathrm{e}}=7612.1$. Moreover, there was no difference between groups and no Group $\times$ Trial interaction $(F \mathrm{~s}<1.0)$. When the two subject groups were analyzed separately, the block effect for the first six data points remained significant in each case $(p s<.001)$. For the second six data points, the block effect was also significant, $F(5,90)=5.63, p<.001, M S_{\mathrm{e}}=9959$. Again, there was no significant difference between groups and no interaction $(F s<1.0)$. When the groups were treated separately, the block effect was significant for the control subjects, 


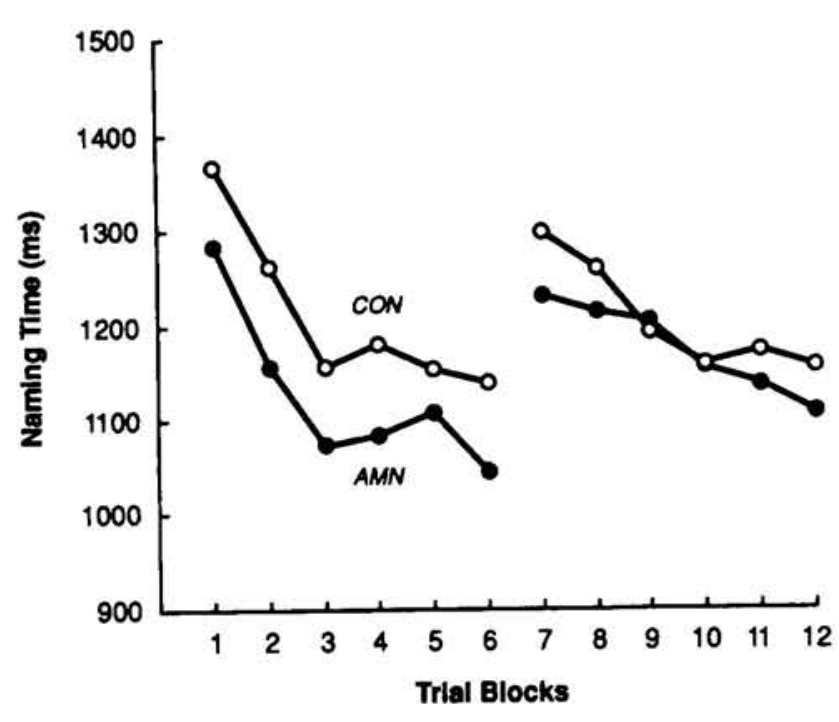

Figure 1. Time required to name the color in which color words (red and green) were printed across 12 blocks of seven trials each. (The same color-word pairs were presented across the first 6 blocks of trials, and then new color-word pairs were presented for the second 6 blocks of trials. AMN $=8$ patients with amnesia; $\mathrm{CON}=12$ control subjects.)

$F(5,55)=3.95, p<.005, M S_{\mathrm{c}}=10504.2$, but fell short of significance for the patients with amnesia, $F(5,35)=2.07$, $p<.10, M S_{\mathrm{e}}=9102.4$.

To determine that the learning effect was specific to the color-word associations, we performed $t$ tests to determine whether the RT for the first block of items in the second set of color-word associations was slower than for the final block of items in the first set of color-word associations. Separate $t$ tests indicated a significant increase in RTs for both subject groups $(p s<.001)$.

We also performed $t$ tests to determine whether any of the learning could be due to a general improvement in the ability to name colors or to inhibit automatic reading responses. Thus, we asked whether RTs for the first block of the second set of color-word associations differed from RTs for the first block of the first set of color-word associations. If these RTs were similar, then the reduction in RTs must be specific to the acquired associations. The results were that both groups named colors in the first block of the second set of trials somewhat more quickly $(1,230$ $\mathrm{ms}$ and $1,297 \mathrm{~ms}$, for patients with amnesia and control subjects, respectively) than the first block of the first set of trials $(1,282 \mathrm{~ms}$ and $1,368 \mathrm{~ms})$, but this difference did not approach significance $(p s>.10)$. Thus, the learning was largely specific to the color-word associations and did not reflect a general improvement in the ability to read incongruent color names.

In contrast with their equivalent performance on naming times, control subjects performed significantly better than amnesic patients on the questionnaire, which asked the subjects questions about the nature of the test, $t(18)=2.5, p<$ .05 . Finally, a striking finding was that both subject groups performed at chance when they were asked to recognize which color words were associated with which colors (Figure 2 , right panel; chance performance $=33.3 \%$ ) .

\section{Experiment 2}

In Experiment 2, we investigated to what extent the learning of new associations depended on the interference inherent in the Stroop task, that is, interference between the color word that had to be ignored and the incongruent color that had to be named. To address this issue, we tested new control subjects and the same patients with amnesia in an analogous color-naming task involving colored words that were not strongly associated with a particular color (e.g., sock, win$d o w$ ). This task (which is referred to here as the neutral task) had a design identical to that of Experiment 1 in that seven words were associated with the same color for six repetitions and then the color-word associations were changed. We asked whether (a) there was a learning curve across the first six trial blocks as was observed in the Stroop paradigm and (b) there was an increase in naming times on the seventh block of trials when the color-word associations were changed.

\section{Method}

Subjects. The same patients with amnesia were tested as in Experiment 1 . We tested 16 control subjects ( 5 men and 11 women) who had not participated in Experiment 1. They were either employees or volunteers at the San Diego Veterans Affairs Medical Center or were retired employees from the University of California,

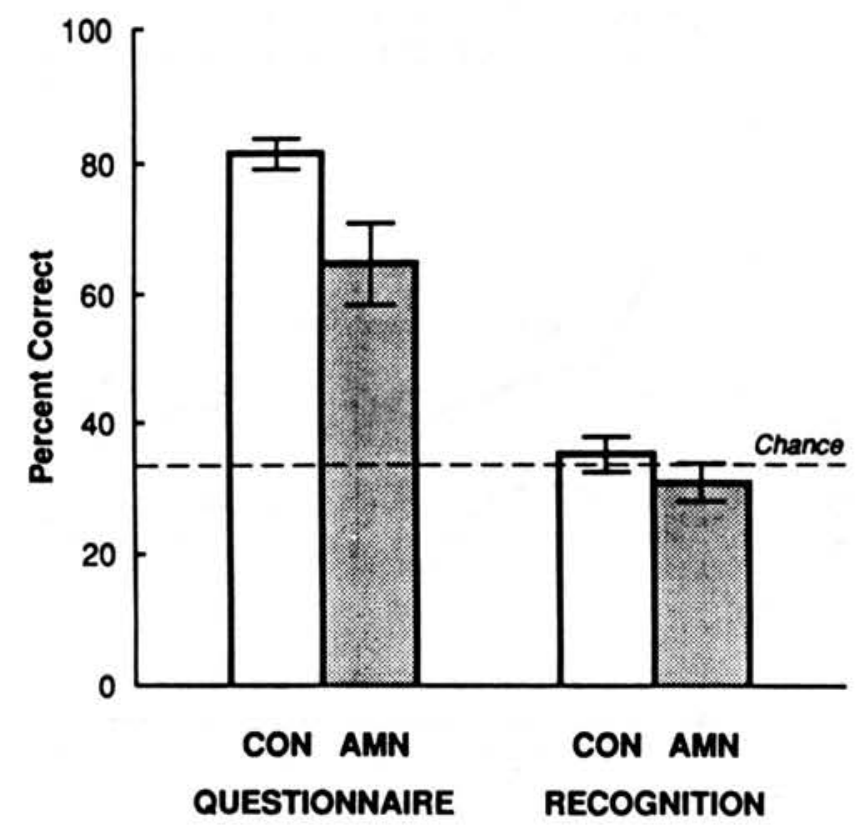

Figure 2. Performance on an eight-item, three-alternative, forced-choice questionnaire about the test procedure (left two bars; chance $=33.3 \%$ ) and on a recognition task for the two different colors in which each word had appeared (right two bars; chance = $33.3 \%$ ). ( $\mathrm{AMN}=8$ patients with amnesia; $\mathrm{CON}=12$ control subjects. Brackets show standard error of the mean.) 
San Diego. They averaged 61.2 years of age (range $=49-73)$ and 14.3 years of education (range $=7.5-18$ ) and obtained WAIS-R subtest scores of 21.1 for Information (range $=15-28$ ) and 56.8 for Vocabulary (range $=41-66$ ). Immediate and delayed recall of a short prose passage was 7.6 and 5.8 segments, respectively.

Materials. The words cloth, chair, stapler, fan, sock, folder, and window were used instead of color names; otherwise the experiment was identical to Experiment 1.

Design and procedure. The procedure was identical to that used in Experiment 1.

\section{Results}

In general, naming times were quicker during this task, which would be expected given the relative ease of the task compared with the Stroop task. A two-way ANOVA revealed a significant block effect during the first portion of the learning curve, $F(5,110)=10.6, p<.001, M S_{\mathrm{e}}=6267.0$. There was no group effect and no Group $\times$ Trial interaction $\left(F_{\mathrm{S}}<\right.$ 2.2 ). When the two groups were analyzed separately, there was a significant learning curve for both groups, $(F \mathrm{~S}>2.6$, $p s<.05$; see Figure 3). For the second group of trials (i.e., when the color-word associations were changed), a two-way ANOVA revealed a significant block effect, $F(5,110)=3.2$, $p<.01, M S_{\mathrm{e}}=5105.2$. There was no group effect and no Group $\times$ Trial interaction $(F s<2.7)$. When the two groups were analyzed separately, the learning curve was significant for the control subjects, $F(5,75)=2.6, p<.05, M S_{\mathrm{e}}=$ 4030.1 , but not for the patients with amnesia $(F<1.6$, $p=.18, M S_{\mathrm{e}}=7409.1$ ).

To determine whether the learning was specific to the color-word associations, we asked whether the naming times for the first block of items in the second set of color-word associations was slower than the final block of items in the

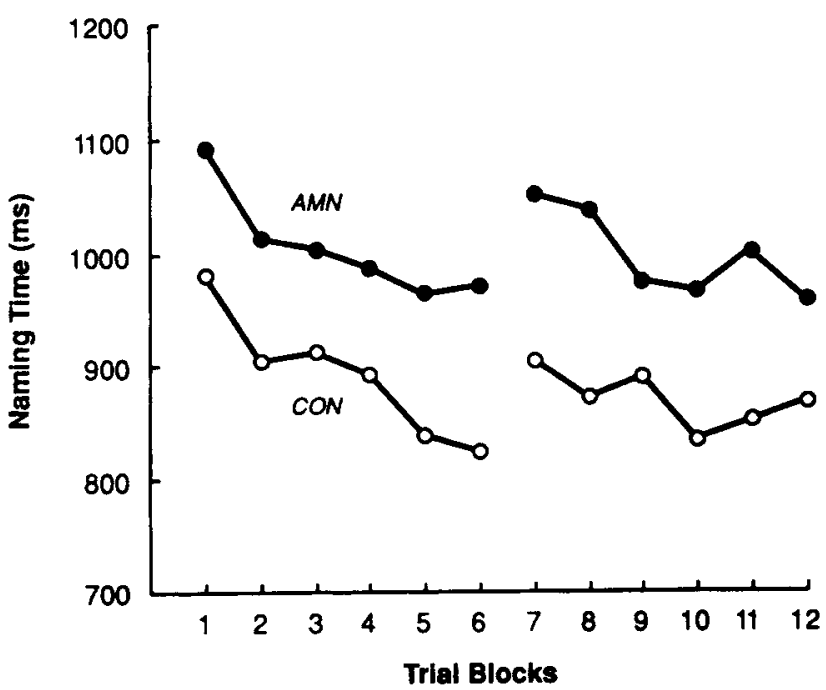

Figure 3. Time required to name the color in which neutral words (sock and window) were printed across 12 blocks of seven trials each. (The same color-word pairs were presented across the first 6 blocks of trials, and then new color-word pairs were presented for the second 6 blocks of trials. AMN $=8$ patients with amnesia; $\mathrm{CON}=16$ control subjects.) first set of color-word associations. Both control subjects and patients with amnesia had slower naming times at the beginning of the second set of trials, thus indicating that both groups did acquire specific color-word associations, ( $t \mathrm{~s}>$ $2.8, p s<.05$ ). This finding suggests that the learning of new associations can occur between neutral words and colors, not just between colors and incongruent color words. Thus, this learning does not depend on there being interference between the elements to be associated.

Finally, we asked whether the naming times for the first block of trials in the second set of color-word associations were significantly faster than the naming times for the first block of trials in the first set of color-word associations. This effect was significant for control subjects (77 ms; $t=2.1$, $p=.05$ ), but not for the patients with amnesia (40 ms; $t<$ 1.0 ), perhaps because the data for patients with amnesia were based on a smaller number of subjects. This finding suggests that the learning during the first six trial blocks was due, in part, to a general improvement in suppressing the reading response. Indeed, it may have been easier to suppress the reading response in the neutral task than in the Stroop task because there was less interference between the word and the color.

\section{Experiment 3}

Experiment 1 demonstrated that changing the association between a color and a word disrupted naming times in the Stroop paradigm, and Experiment 2 obtained the same result in a related neutral task. Both tasks required subjects to attend to both features of the stimuli (the word, because it is automatically read, and the color, to perform the task). An interesting question is whether attending to the two relevant features of the stimuli was necessary for implicit learning of new associations. To address this issue, we changed the typecase of the words and held the color-word associations constant. If attention to the relevant stimuli is necessary for the learning of new associations, then this manipulation should have the same effect as changing the color-word associations. However, if attention to the relevant dimensions of the stimuli is not necessary for the learning of new associations, then naming times should not be disrupted.

\section{Method}

Subjects. The same patients with amnesia were tested as in the previous experiments. We tested 12 control subjects $(6$ men and 6 women) who had not participated in Experiment 1 or 2 . They were either employees or volunteers at the San Diego Veterans Affairs Medical Center or were retired employees from the University of California, San Diego. They averaged 66.5 years of age (range $=$ $50-79$ ) and 14.8 years of education (range $=10-19$ ) and obtained WAIS-R subtest scores of 23.4 for Information (range $=17-27$ ) and 57.3 for Vocabulary (range $=50-64$ ). Immediate recall and delayed recall of a short prose passage were 7.0 and 6.0 segments, respectively.

Materials. The materials were the same as those used in Experiment 1.

Design and procedure. The procedure was identical to that used in Experiment 1 except that after the first six blocks of trials, 
the typecase changed (from either uppercase to lowercase or vice versa). The color-word associations remained stable throughout the experiment. On the basis of the same criteria used in Experiment $1,6.5 \%$ of the trials were eliminated.

\section{Results}

We measured naming times across 12 blocks of trials, each block consisting of seven trials. As in Experiments 1 and 2, there was a significant learning curve across the first six trial blocks, $F(5,90)=6.3, p<.001, M S_{\mathrm{e}}=18602.0$, (see Figure 4 ). When the two subject groups were analyzed separately, the block effect for the first six data points was significant for the control group $(p<.001)$ but did not reach significance for the patients with amnesia $(p=.17)$. However, both groups showed a significant decrease in naming times from the first block to the sixth block, $(t \mathrm{~s}>3.1, p \mathrm{~s}<.01$; control subjects $1,430.9 \mathrm{~ms}$ vs. $1,234.6 \mathrm{~ms}$ for the first and the sixth block, respectively; patients with amnesia, $1,285.8 \mathrm{~ms}$ vs. $1,094.4 \mathrm{~ms}$ ). The important finding was that no disruption was observed in either group between the final block of trials in one typecase and the first block of trials in the other typecase $(t \mathrm{~s}<1.0)$. Thus, we found no evidence for implicit learning of associations involving an unattended stimulus feature, that is, typecase. Learning did not continue across the second set of trials, perhaps because maximum learning had already occurred.

\section{Experiment 4}

This experiment asked whether the successful learning of new associations depended on immediate memory, which is intact in amnesia. Because only $10 \mathrm{~s}$ intervened between a

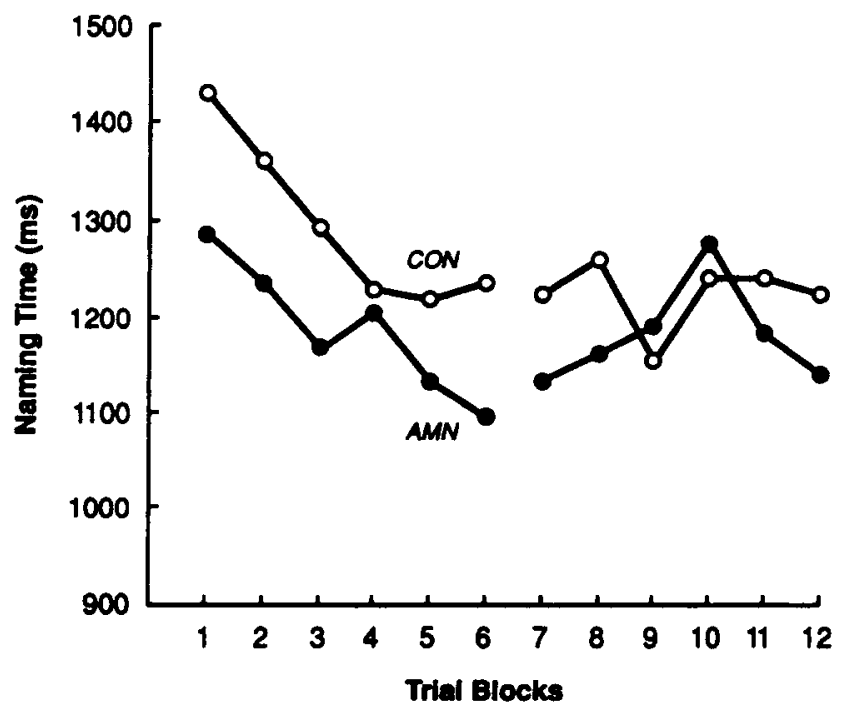

Figure 4. Time required to name the color in which words were printed across 12 blocks of trials. (The same color-word pairs were presented for all 12 blocks, but an irrelevant feature of the stimuli [typecase] was changed after the first 6 blocks and remained changed for the second 6 blocks of trials. AMN $=8$ patients with amnesia; $\mathrm{CON}=12$ control subjects.) particular color-word association and its repetition, it is possible that subjects might have held the associative information in immediate memory. To explore this possibility, we introduced a 5-min delay after the first six blocks. After the delay, the same color-word associations were presented to the subject, and we examined whether the reduction in RTs was sustained across the delay.

\section{Method}

Subjects. The same patients with amnesia were tested as in Experiments 1-3, except Patient VF, who was unavailable for testing.

Seven men and 5 women, who had not participated in Experiments $1-3$, served as a control group for the patients with amnesia. They were either employees or volunteers at the San Diego Veterans Affairs Medical Center or were retired employees from the University of California, San Diego. They averaged 62.8 years of age (range $=53-76)$ and 13.9 years of education (range $=11-18$ ) and obtained WAIS-R subtest scores of 21.5 for Information (range $=$ $17-25$ ) and 54.3 for Vocabulary (range $=46-64$ ). Immediate recall and delayed recall of a short prose passage were 6.5 and $5.1 \mathrm{seg}$ ments, respectively.

Materials. The materials were identical to those used in Experiment 1.

Design and procedure. The procedure was identical to that used in Experiment 1 except that after the first six blocks of trials in which a color was associated with a particular color word a 5-min, conversation-filled delay was interposed before the next phase of the experiment. After the delay, 42 more trials of the same colorword associations were given. As in Experiment 1, the experimenter recorded trials as invalid if a subject made an error by reading the word on the screen rather than naming the color that the word was printed in, or if the voice-activated relay was not triggered correctly. Trials were eliminated for $5.9 \%$ of the trials for patients with amnesia and for $4.6 \%$ of the trials for control subjects.

\section{Results}

As in Experiments 1 and 2, we measured RTs across 12 blocks of trials; each block consisted of seven trials. The results were that RTs improved for both groups during the first block of trials and then were sustained at this level after the 5-min delay (Figure 5). A two-way ANOVA revealed a significant block effect prior to the 5-min delay, $F(5,85)=$ 14.0, $p<.001 ; M S_{\mathrm{e}}=8296.1$. There was no difference between groups and no interactions $(F \mathrm{~s}<1.0)$. The block effect was also significant when the two groups were considered separately $(p s<.01)$. No further reduction in RTs occurred after the delay, which suggests that the learning of color-word associations had reached the maximum value ( $F$ $<1.0$ ). Further analysis showed that the learning that had occurred during the first six trial blocks persisted without decrement across the 5-min delay. Thus, for both groups, the response times for the first block of trials after the delay were significantly faster than the response times for the first block of trials in the first set $(p s<.01)$ and not significantly different from the sixth trial block $(p s>.10)$. These results provide strong evidence that the learning of new associations between a color and a word is not dependent on immediate memory $(p s>.10)$. 


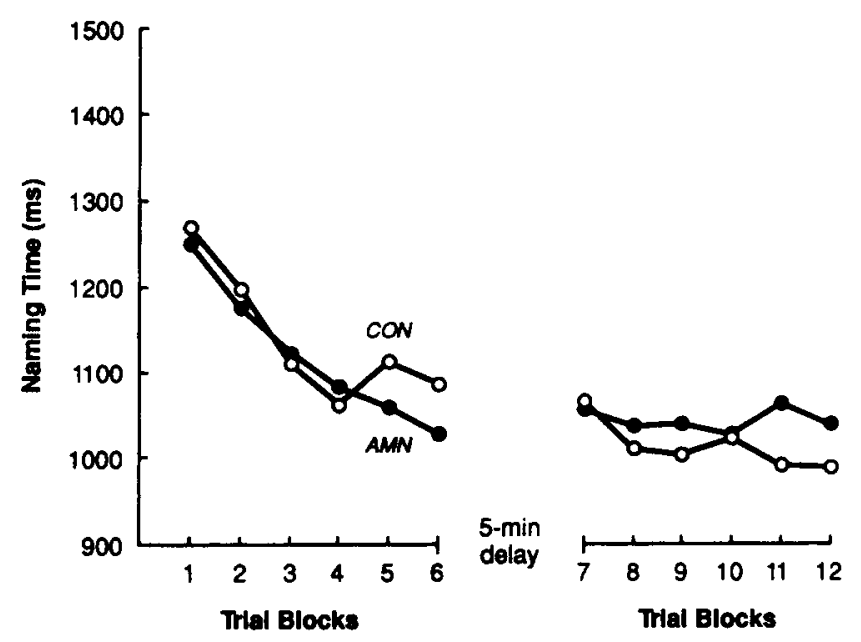

Figure 5. Time required to name the color in which a word was printed across 12 blocks of 7 items each. (The same color-word pairs were presented during all 12 blocks of trials, and a 5-min delay was introduced after the 6th block. AMN $=7$ patients with amnesia; $\mathrm{CON}=12$ control subjects.)

\section{General Discussion}

The present studies demonstrated robust implicit learning of new associations across multiple trials. Evidence for the gradual implicit learning of new associations has been reported previously, both for associations that are acquired within trials and for associations that are acquired between trials (Cleeremans \& McClelland, 1991; Hartman et al., 1989; Lewicki et al., 1987; Musen \& Squire, 1993; Willingham et al., 1989). In the present experiments, this phenomenon was found to extend outside the verbal domain. Control subjects and patients with amnesia acquired associations between colors and words at the same rate despite being unaware of the associations that had been learned. Indeed, both groups of subjects performed at chance on a recognition memory test that required them to identify which two colors each word had appeared in during the test.

The results from the Stroop task in Experiment 1 indicate that the color information is acquired, because performance declined when the color of each word was abruptly changed. This result can be contrasted with the findings from a different study (Treisman, 1992) that showed that changing the color of a stimulus did not reduce the facility with which the response was made. A critical difference between our study and the one reported by Treisman was that our task required that colors be processed, whereas Treisman's did not. That is, our study required that subjects treat the components of the stimuli separately (as colors and words) rather than as surface features of a unified stimulus that could potentially be ignored. Others have also reported that when features of the stimulus are made relevant to the task, performance on priming tasks can be affected when these features are changed (Graf \& Ryan, 1990). Importantly, when we changed an irrelevant feature of the stimuli (i.e., typecase) in Experiment 3, the disruption in naming times was not observed. Thus, we suggest that implicit acquisition of new associations can be acquired when both components of the information to be associated are attended to.

It is often difficult to determine whether two attributes of a stimulus should be considered to be two features of a single stimulus or two features to be associated. Every object has multiple features, for example, a printed word has a particular length, size, font, and color. However, when one reads a word, these features may not all be attended to-the dominant stimulus information is the word itself. In such a case, it may be useful to think of the word as a single stimulus having several features. In contrast, in the present studies the stimulus was a word printed in a color, and the response required that subjects attend to the color. Because the reading of the word is automatic, both of these properties of the stimulus must be processed. Thus, in our study, the word and its color carry equal weight, and we therefore discuss our results in terms of acquiring new associations between colors and words. Furthermore, Experiment 3 demonstrated that, when the color and the word are attended to but an irrelevant feature is manipulated, this change does not disrupt naming times. Changing an irrelevant feature had no effect either because subjects did not attend to this feature (typecase) or because the task did not require the subject to access information about typecase.

An attention-demanding task such as the Stroop task appears to provide a good paradigm for studying the implicit acquisition of new associations because implicit memory for new associations can be facilitated by attention. For example, Hartman et al. (1989) suggested that implicit learning of new associations occurred only when the task was attention demanding and not when the task could be performed automatically. Thus, it is possible that the attentional demands of the task facilitate implicit learning of new associations.

In the Stroop paradigm, the word is processed even though the subject attempts to ignore it. The fact that the word is processed is evidenced by the increase in naming times when the color-word associations are changed. Other studies have also indicated that intentionally ignored features are processed. For example, in studies reporting negative priming effects (Allport, Tipper, \& Chmiel, 1985; Tipper, 1985), two overlapping figures are presented (one in green and one in red). The subject's task is to respond to a figure in a specific color and to ignore the other figure that is printed in the other color. The manipulation of interest was that on some trials the unattended figure became the relevant figure on the subsequent trial. The RTs were slower when the selected shape had been presented as the ignored item on the preceding trial.

In summary, the present findings provide evidence for gradual acquisition of new nonverbal associations. The learning is acquired across multiple trials in the absence of declarative information about the task (Experiment 1), the effect is not dependent on interference (Experiment 2), no disruption in learning is observed when an irrelevant feature of the stimuli is changed (Experiment 3), and the effect does not depend on immediate memory (Experiment 4). The increase in naming times that occurred when the color-word associations changed, as compared with the absence of an effect when color was altered in a previous experiment (Treisman, 1992), highlights the importance of response 
demands on performance in implicit memory tasks. That is, color information may not have been encoded in Treisman's study, either because color was irrelevant to the task or because the task was not attention demanding. Alternatively, color information may have been stored but not tapped because it was irrelevant to the response. In our study, color was attended to because subjects had to name the color of each item. And, importantly, when we changed an irrelevant feature (typecase) we did not observe a disruption in naming times. This finding further supports the claim that features that are irrelevant to the task do not affect performance. Future experiments that involve changes in stimuli from study to test and different encoding and response demands can be expected to further improve the understanding of implicit memory.

\section{References}

Allport, D. A., Tipper, S. P., \& Chmiel, N. R. J. (1985). Perceptual integration and postcategorical filtering. In M. Posner \& O. S. M. Marin (Eds.), Attention and performance XI (pp. 107-132). Hillsdale, NJ: Erlbaum.

Biederman, I., \& Cooper, E. E. (1991). Evidence for complete translational and reflectional invariance in visual object priming. Perception, 20, 585-593.

Biederman, I., \& Cooper, E. E. (1992). Size invariance in visual object priming. Journal of Experimental Psychology: Human Perception and Performance, 18, 121-133.

Cave, C. B., \& Squire, L. R. (1992). Intact and long-lasting repetition priming in amnesia. Journal of Experimental Psychology: Learning, Memory, and Cognition, 18, 509-520.

Cermak, L. S., Bleich, R. P., \& Blackford, S. P. (1988). Deficits in implicit retention of new associates by alcoholic Korsakoff patients. Brain and Cognition, 1, 145-156.

Cermak, L. S., Talbot, N., Chandler, K., \& Wolbarst, L. R. (1985). The perceptual priming phenomenon in amnesia. Neuropsychologia, 23, 615-622.

Cermak, L. S., Verfaellie, M., Milberg, W., Letourneau, L., \& Blackford, S. (1991). A further analysis of perceptual identification priming in alcoholic Korsakoff patients. Neuropsychologia, 29, $725-736$

Cleeremans, A., \& McClelland, J. L. (1991). Learning the structure of event sequences. Journal of Experimental Psychology: General, 120, 235-253.

Cooper, L. A., Schacter, D. L., Ballesteros, S., \& Moore, C. (1992). Priming and recognition of transformed three-dimensional objects: Effects of size and reflection. Journal of Experimental Psychology: Learning, Memory, and Cognition, 18, 43-57.

Feustel, T. C., Shiffrin, R. M., \& Salasoo, A. (1983). Episodic and lexical contributions to the repetition effect in word identification. Journal of Experimental Psychology: General, 112, 309-346.

Gabrieli, J. D. E., Milberg, W., Keane, M. M., \& Corkin, S. (1990). Intact priming of patterns despite impaired memory. Neuropsychologia, 28, 417-427.

Gilbert, J., Levee, R., \& Catalano, K. (1968). A preliminary report on a new memory scale. Perceptual and Motor Skills, 27, 277278.

Graf, P., \& Ryan, L. (1990). Transfer-appropriate processing for implicit and explicit memory. Journal of Experimental Psychology: Learning, Memory, and Cognition, 16, 978-992.

Graf, P., \& Schacter, D. L. (1985). Implicit and explicit memory for new associations in normal and amnesic subjects. Journal of $E x$ - perimental Psychology: Learning, Memory, and Cognition, 11, 501-518.

Graf, P., \& Schacter, D. L. (1987). Selective effects of interference on implicit and explicit memory for new associations. Journal of Experimental Psychology: Learning, Memory, and Cognition, 13, 45-53.

Graf, P., \& Schacter, D. L. (1989). Unitization and grouping mediate dissociations in memory for new associations. Journal of Experimental Psychology: Learning, Memory, and Cognition, 15, 930-940.

Haist, F., Musen, G., \& Squire, L. R. (1991). Intact priming of words and nonwords in amnesia. Psychobiology, 19, 275-285.

Hartman, M., Knopman, D., \& Nissen, M. J. (1989). Implicit learning of new verbal associations. Journal of Experimental Psychology: Learning, Memory, and Cognition, 15, 1070-1082.

Jacoby, L. L. (1983). Perceptual enhancement: Persistent effects of an experience. Journal of Experimental Psychology: Learning, Memory, and Cognition, 9, 21-38.

Jacoby, L. L., \& Dallas, M. (1981). On the relationship between autobiographical memory and perceptual learning. Journal of Experimental Psychology: General, 3, 306-340.

Jacoby, L. L., \& Hayman, G. (1987). Specific visual transfer in word identification. Journal of Experimental Psychology: Learning, Memory, and Cognition, 13, 456-463.

Janowsky, J. S., Shimamura, A. P., Kritchevsky, M., \& Squire, L. R. (1989). Cognitive impairment following frontal lobe damage and its relevance to human amnesia. Behavioral Neuroscience, $103,548-560$.

Jolicouer, P. (1985). The time to name disoriented natural objects. Memory \& Cognition, 13, 289-303.

Kahneman, D., \& Treisman, A. (1984). Changing views of attention and automaticity. In R. Parasuraman \& J. Beatty (Eds.), Varieties of attention (pp. 29-61). San Diego, CA: Academic Press.

Kaushall, P. I., Zetin, M., \& Squire, L. R. (1981). A psychosocial study of chronic, circumscribed amnesia. Journal of Nervous and Mental Disease, 169, 383-389.

Kersteen-Tucker, Z. (1991). Long-term repetition priming with symmetrical polygons and words. Memory \& Cognition, 19, 3743.

Kritchevsky, M., \& Squire, L. R. (1993). Permanent global amnesia with unknown etiology. Neurology, 43, 326-332.

Kritchevsky, M., Squire, L. R., \& Zouzounis, J. A. (1988). Transient global amnesia: Characterization of anterograde and retrograde amnesia. Neurology, 38, 213-219.

Lewicki, P., Czyzewska, M., \& Hoffman, H. (1987). Unconscious acquisition of complex procedural knowledge. Journal of Experimental Psychology: Learning, Memory, and Cognition, 13, 523-530.

Masson, M. E. J. (1986). Identification of typographically transformed words: Instance-based skill acquisition. Journal of Experimental Psychology: Learning, Memory, and Cognition, 12, 479-488.

Mattis, S. (1976). Dementia Rating Scale. In R. Bellack \& B. Keraso (Eds.), Geriatric psychiatry (pp. 77-121). New York: Grune \& Stratton.

Mayes, A. R., \& Gooding, P. (1989). Enhancement of word completion priming in amnesics by cuing with previously novel associates. Neuropsychologia, 27, 1057-1072.

Moscovitch, M., Winocur, G., \& McLachlan, D. (1986). Memory as assessed by recognition and reading time in normal and memory-impaired people with Alzheimer's disease and other neurological disorders. Journal of Experimental Psychology. General, 115, 331-347.

Musen, G., \& Squire, L. R. (1991). Normal acquisition of novel 
verbal information in amnesia. Journal of Experimental Psychology: Learning, Memory, and Cognition, 17, 1095-1104.

Musen, G., \& Squire, L. R. (1992). Nonverbal priming in amnesia. Memory \& Cognition, 20, 441-448.

Musen, G., \& Squire, L. R. (1993). On the implicit learning of novel associations by amnesic patients and normal subjects. Neuropsychology, 7, 119-135.

Musen, G., \& Treisman, A. (1990). Implicit and explicit memory for visual patterns. Journal of Experimental Psychology: Learning, Memory, and Cognition, 16, 127-137.

Osterrieth, P. A. (1944). Le test de copie d'une figure complexe. [The test of copying a complex figure]. Archives de Psychologie. 30, 206-356.

Press, G., Amaral, D. G., \& Squire, L. R. (1989). Hippocampal abnormalities in amnesic patients revealed by high-resolution magnetic resonance imaging. Nature, 341, 54-57.

Rey, A. (1964). L'examen clinique psychologie [Clinical psychological test]. Paris: Presses Universitaires de France.

Roediger, H. L., III, \& Blaxton, T. A. (1987). Effects of varying modality, surface features, and retention interval on priming in word-fragment completion. Memory \& Cognition, 15, 379-388.

Rueckl, J. G. (1990). Similarity effects in word and pseudoword repetition priming. Journal of Experimental Psychology: Learning, Memory, and Cognition, 16, 374-391.

Salasoo, A., Shiffrin, R. M., \& Feustel, T. C. (1985). Building permanent codes: Codification and repetition effects in word identification. Journal of Experimental Psychology: General, 114, $50-77$.

Scarborough, D. L., Cortese, C., \& Scarborough, H. S. (1977). Frequency and repetition effects in lexical memory. Journal of Experimental Psychology: Human Perception and Performance, 3, $1-17$.

Schacter, D. L., Chiu, C. Y. P., \& Ochsner, K. N. (1993). Implicit memory: A selective review. Annual Review of Neuroscience, 16 , $159-182$.

Schacter, D. L., Cooper, L. A., \& Delaney, S. M. (1990). Implicit memory for unfamiliar objects depends on access to structural descriptions. Journal of Experimental Psychology: General, 119, 5-24.

Schacter, D. L., Cooper, L. A., Tharan, M., \& Rubens, A. B. (1991). Preserved priming of novel objects in patients with memory disorders. Journal of Cognitive Neuroscience, 3, 118-131.

Schacter, D. L., \& Graf, P. (1986). Effects of elaborative processing on implicit and explicit memory for new associations. Journal of Experimental Psychology: Learning, Memory, and Cognition, 12, $432-444$.

Schacter, D. L., \& Graf, P. (1989). Modality specificity of implicit memory for new associations. Journal of Experimental Psychol ogy: Learning, Memory, and Cognition, 15, 3-21.

Shimamura, A. P., Jernigan, T. L., \& Squire, L. R. (1988). Korsakoff's syndrome: Radiological (CT) findings and neuropsychological correlates. Journal of Neuroscience, 8, 4400-4410.

Shimamura, A. P., \& Squire, L. R. (1989). Impaired priming of new associations in amnesia. Journal of Experimental Psychology: Learning, Memory, and Cognition, 15, 721-728.

Squire, L. R., Amaral, D. G., \& Press, G. A. (1990). Magnetic resonance measurements of hippocampal formation and mammillary nuclei distinguish medial temporal lobe and diencephalic amnesia. Journal of Neuroscience, 10, 3106-3117.

Squire, L. R., Amaral, D. G., Zola-Morgan, S., Kritchevsky, M., \& Press, G. (1989). Description of brain injury in the amnesic patient N. A. based on magnetic resonance imaging. Experimental Neurology, 105, 23-25.

Squire, L. R., Knowlton, B. J., \& Musen, G. (1993). The structure and organization of memory. Annual Review of Psychology, 44. $453-495$.

Squire, L. R., \& Shimamura, A. P. (1986). Characterizing amnesic patients for neurobehavioral study. Behavioral Neuroscience. $100,866-877$

Stroop, J. R. (1935). Studies of interference in serial verbal reactions. Journal of Experimental Psychology, 18, 643-662.

Teuber, H. L., Milner, B., \& Vaughan, H. G. (1968). Persistent anterograde amnesia after stab wound of the basal brain. Neuropsychologia, 6, 267-282.

Tipper, S. P. (1985). The negative priming effect: Inhibitory effect of ignored primes. Quarterly Journal of Experimental Psychology, 37A, 571-590.

Treisman, A. (1992). Perceiving and re-perceiving objects. American Psychologist, 47, 862-875.

Warrington, E. K. (1984). Recognition memory test. Windsor, England: FER-Nelson.

Whitlow, J. W., Jr., \& Cebollero, A. (1989). The nature of word frequency effects on perceptual identification. Journal of Experimental Psychology: Learning, Memory, and Cognition, 15, 643656.

Willingham, D. B., Nissen, M. J., \& Bullemer, P. (1989). On the development of procedural knowledge. Journal of Experimental Psychology: Learning, Memory, and Cognition, 15, 1047-1060.

Received May 26, 1992

Revision received November 25, 1992 Accepted November 27, 1992 